\title{
Leading-Edge Velocities and Lifted Methane Jet Flame Stability
}

\author{
W. Wang and K. M. Lyons \\ Department of Mechanical and Aerospace Engineering, North Carolina State University, Raleigh, NC 27695-7910, USA \\ Correspondence should be addressed to K. M. Lyons, lyons@eos.ncsu.edu
}

Received 13 August 2009; Revised 16 December 2009; Accepted 17 February 2010

Academic Editor: Lea-Der Chen

Copyright ( 2010 W. Wang and K. M. Lyons. This is an open access article distributed under the Creative Commons Attribution License, which permits unrestricted use, distribution, and reproduction in any medium, provided the original work is properly cited.

\begin{abstract}
Current interest exists in understanding reaction-zone dynamics and mechanisms with respect to how they counterpropagate against incoming reactants. Images of flame position and flow-field morphology are presented from flame chemiluminescence and particle image velocimetry (PIV) measurements. In the present study, PIV experiments were carried out to measure the methane jet lifted-flame flow-field velocities in the vicinity of the flame leading edge. Specifically, velocity fields within the hightemperature zone were examined in detail, which complements previous studies, whose prime focus is the flow-field upstream of the high-temperature boundary. PIV data is used not only to determine the velocities, but, along with chemiluminescence images, to also indicate the approximate location of the reaction zone (further supported by/through the leading-edge flame velocity distributions). The velocity results indirectly support the concept that the flame is anchored primarily through the mechanism of partially premixed flame propagation.
\end{abstract}

\section{Introduction}

The stabilization mechanisms of turbulent jet lifted flames have long been the topic of combustion research and the major studies have been reviewed (Pitts [1] and Lyons [2]). The premixed flame theory, the scalar dissipation-rate theory, the turbulence intensity theory, large-eddy dissipation theory, and edge flame concept are typical theories employed.

The premixed flame theory implies that the flame base is fully premixed and at stoichiometric condition [3-5]. However, studies show that fuel-air mixtures upstream of the flame are subject to significant turbulent fluctuation and cannot be classified as only fully premixed [6-8]. The scalar dissipation-rate theory claims that the extinction of diffusion flamelets controls jet lifted-flame stabilization and flame base stabilizes where the scalar dissipation rate is below a critical value [9]. However, studies have shown that the scalar dissipation rates do not reach levels thought to cause extinction of the leading edge based on comparison with extinction data for counterdiffusion flames [7]. The turbulence intensity theory argues that turbulence intensity at the base controls the flame speed [10]. Some studies indicate that the lifted-flame base is located at a radial location that is far from the centerline, where turbulence intensities are small [11]. The large-eddy dissipation theory $[12,13]$, which is involved in many global theories such as autoignition, large-eddy structures, and scalar dissipationrate theory, needs more investigation. The edge flame concept $[11,14,15]$, consistent with triple flame structures, assumes that the flame leading edge can propagate upstream to counter the local flow field and stabilize the flame.

From the studies on lifted jet flame stabilization so far, the current understanding is that a partially premixed type of edge flame may be a successful emerging model. Given that a prime importance of experimental data is to lead model development, one of the important parameters to be assessed is the velocity field at the lifted-flame base edge. Many new experimental research efforts have been performed in recent years, due in part to developments in optical techniques such as particle image velocimetry (PIV). Advances in PIV are particularly beneficial for jet flame studies since they provide a two-dimensional planar measurement of velocity, which can produce plane axial velocities conditioned on instantaneous reaction-zone leading-edge position. One such study by Muñiz and Mungal [16] involved the application of PIV to a lifted methane jet flame over the range of Re from 3800 to 22,000 . Supported by their results, they argued that the 
reaction zone seeks out relatively low-velocity regions of the flow field and that the flame propagates to fulfill the criterion of flame propagation counterbalancing the incoming flow of reactants. This study also examined the reaction zone for evidence of triple flame-like behavior at the flame's leading edge (Ruetsch et al. [17]). Mansour et al. [18] also argued that triple flame structures can be composed using multiple species concentration images.

Watson et al. [19] sought to identify edge flame structures in lifted flames explicitly, using $\mathrm{CH}$ fluorescence to infer the reaction-zone location. The distortion of the edge flame structure noted by Veynante et al. [20], however, makes direct identification of the various branches difficult in turbulent flames, and controversy still exists as to the regimes for their existence.

$\mathrm{Su}$ et al. [21] argued that statistics of the fuel mole fraction at the instantaneous high-temperature interface shows that the flame stabilization point does not generally correspond to the most upstream point on the interface (called here the leading point), because the mixture there is typically too lean to support combustion. Instead, they contended that the flame stabilization point lies closer to the jet centerline relative to the leading point. Conditional axial velocity statistics indicated that the mean axial velocity at the flame front is $\approx 1.8 s_{L}$ where $s_{L}$ is the stoichiometric laminar flame speed. The PIV seeding used was a glycerol-water fog, which evaporates at elevated temperatures. The flame-base edge was not as accurately indicated at the high-temperature interface by this technique (as with tracking combustion intermediates) and it is possible that the predicted position of the flame base was impacted by such inaccuracies.

Some researchers who support edge flames theory such as Upatnieks et al. [11] maintained that two propagation velocities of the edge flame are important. One is the actual burning velocity of the flame relative to the disturbed flow, which is of the order of the laminar burning velocity. The second is the effective propagation velocity of the whole edge flame. It is in this spirit of examining the bulk flame motion into the reactants in the laboratory frame that the following research is reported.

The objectives of this investigation are to use the methane jet flame chemiluminescence images and raw PIV data to determine the flame position and flame edges. As opposed to previous studies, which tend to examine velocities upstream of the reaction zone, the present study focuses on velocities crossing into the high-temperature zone. In this approach, the velocity field in the vicinity of the upstream portion of the reaction zone is examined in detail, along with flow behavior in the surrounding regions. Given the state of the field, these velocity fields are examined for elements that support the existence of premixed branches (i.e., flow steering across anchor- , or partial anchor- , shaped reaction zones). The velocities found are compared to the laminar averaged premixed flame speeds and the variation of the velocities through the reaction zone is investigated. While studies of reactive scalars at the leading edge yield unclear results as to the morphology of the various flame branches, the details of the velocity jumps inside the high-temperature zone are quite consistent with those of a partially premixed flame region. Thus, a contribution of this paper is in the area of supporting partially premixed combustion through velocity field data, rather than through arguments based on reactive-scalar field data.

\section{Experimental Arrangement}

The experiments were carried out at the Applied Energy Research Laboratory of North Carolina State University. The schematic representation of the experimental setup for the simultaneous particle image velocimetry (PIV) measurements is shown in Figure 1(a). The jet flame burner is a stainless steel pipe nozzle with an inner diameter of 3.5 millimeters $(\mathrm{mm})$ and a length of 50 centimeters $(\mathrm{cm})$ for a fully developed flow. The schematic of burner is shown in Figure 1(b). The apparatus is installed vertically, provides a top-hat velocity at the nozzle's exit, and delivers 99\% pure methane. A cylindrical tank filled with the 0.5 micrometer $(\mu \mathrm{m})$ silica is connected with the methane fuel source and burner pipe to achieve seeding. The PIV system consists of two Nd:YAG lasers, a dye lasers, a digital high-speed camera (resolution with $1008 \times 1018$ ), and various optics (labeled as numbers of 1-11). The two lasers are built on a single compact platform (Continuum Minilite PIV), providing a symmetrical output beam at 532 nanometers $(\mathrm{nm})$. It consists of the two pulses with equivalent beam uniformity and polarization, each at an energy of 25 millijoules $(\mathrm{mJ})$. The time separation between the two pulses can be set to as low as 10 nanoseconds (ns). The trigger, connected to the lasers and the high-speed camera, can activate the laser and camera simultaneously.

The flow parameters examined are at a jet exit velocity as $22.6 \mathrm{~m} / \mathrm{s}$, giving a Reynolds number $\mathrm{Re}=u D / v=4794$ without coflow. Here, $u$ is the jet exit velocity, $D$ presents jet diameter, and $v$ presents kinematic viscosity, respectively. The lift-off height achieved is approximately $3.1 \mathrm{~cm}$. The laser sheet covers the full extent of the flame leading edge.

All of the images are in the same coordinate system with the $76 \mathrm{~mm} \times 77 \mathrm{~mm}$ field of view centered at $38 \mathrm{~mm}$ downstream (10.86 nozzle diameters). The raw PIV data is examined and processed using PIVlab 2000 software (Han and Mungal [22]) in an iterative processing technique proposed by Westerweel [23]. It went through seven iterations with decreasing offset as the displacement calculations converged. The final window size was limited to $64 \times 64$ pixels with $50 \%$ overlap. Each PIV image resolution is slightly different because of changes in the spacing ranges of the flame images. The resolutions range from $0.5 \sim$ 1.2 vectors $/ \mathrm{mm}$.

\section{Results and Discussion}

Figure 2(a) shows the streamlines for triple flames with small and large mixing thicknesses. Ruetsch et al. [17] superimposed the two streamline patterns to determine how the flow redirection differs in these two cases. Both of the situations have similar morphologies (with divergences near the triple flame edge from both lean and rich sides), which 


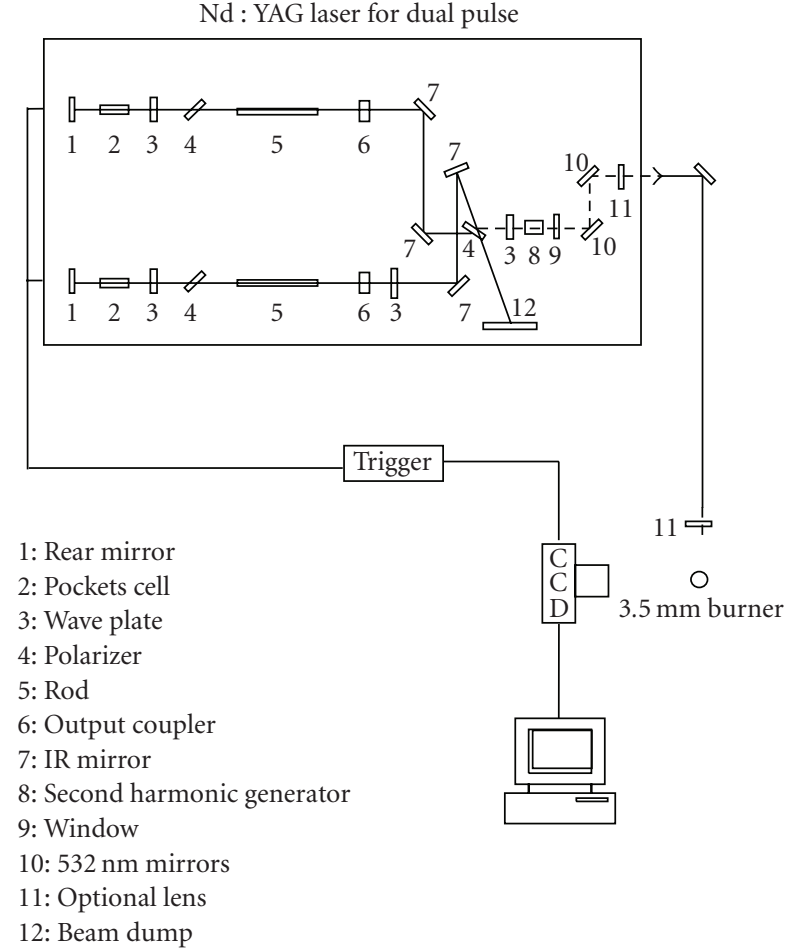

(a)
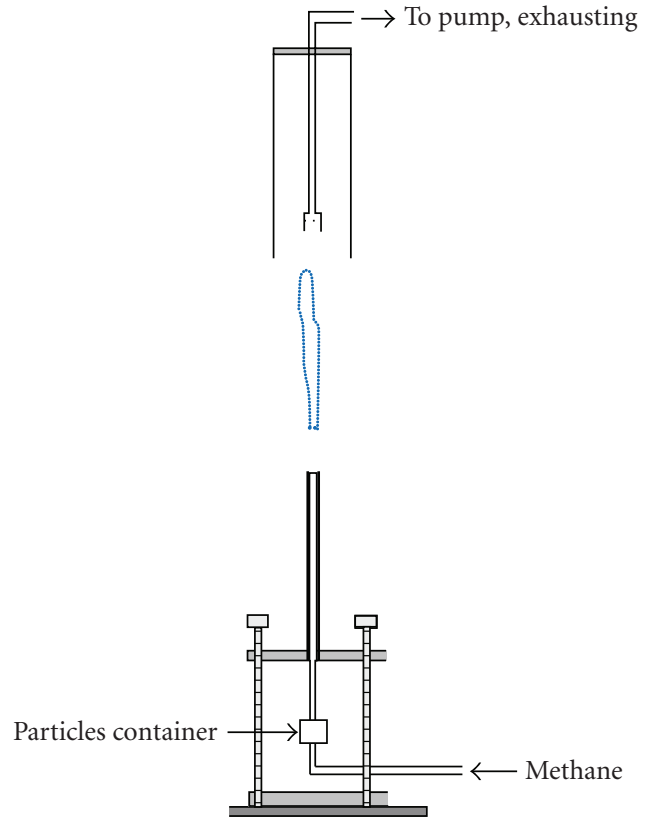

(b)

FIgURE 1: (a) Schematic of PIV experimental arrangement. (b) Schematic of burner.

is one of triple flames characteristics, yet the flame structure width is quite different, and the effect of the width on the streamline divergence is minimal. This concept prompted the study to examine the velocity fields in detail, rather than proceed with further high-resolution scalar measurements, and look for trends in the velocity fields and streamlines in the vicinity of the leading edge. Figure 2(b) shows the schematic of a similar laminar triple flame propagating into a fuel concentration gradient. The flame structure is indicated by isocontour lines of the reaction rate. The bottom graph shows profiles of the horizontal velocity component along stoichiometric line for a propagating triple flame (-) and a planar premixed flame (- - ) (from Ruestch et al. [17]). At the triple flame points, the flame speed is the same as that of the premixed, and in the flame zone, downstream next to the triple flame point, the flame speed is approximately 2.4 times the triple flame point speed (2.4 times the laminar flame speed). Also shown is the pure premixed flame assumption downstream, with a constant 4 times the premixed laminar flame speed.

In this study, high-temperature zones are determined using the following strategy: for every flame image, the domain with considerable flame fluorescence is examined (i.e., bright luminescent background (as opposed to bright particles)). In addition, in bright zones, high-temperature zones (with low-density seeded particles) grayscales are more uniform locally than nonflame zones (with highdensity seeded particles). Therefore, in bright zones, the gradients of grayscales in flame zones are much smaller than those of nonflame zones. Thus, we have estimations of regions of chemical reaction using the seed particles as well as chemiluminescence magnitudes. The locations of high-temperature zones are estimated empirically using the second derivate magnitudes of image grayscales less than 2. Figure 3(a) is a series of the experimental image results (including 6 cases from case 1 to case 6 ) and shows the red zones as the proposed high-temperature zones.

Compared to other studies of jet flames with seeded coflow, the study of free jet flames in the present paper focuses only on the hot zone. Inside the determined flame zones, in the vicinity of the large velocity gradients near the flame-base edge, two groups of points are selected. One group (called group 2, covered by a polygon box) contains abutting lower velocity points, which are at the flame edge. The other group (called group 1, located higher than the polygon box, but sometimes somewhat overlapping) is made up of abutting high velocities points, which are next to the flame edge downstream portion. Not all polygon boxes of left and right flame edges are labeled for each case because sometimes the vector field cannot cover the whole flame edges or noises that are too big. Further downstream, the magnitudes of velocities are even larger than those of group 1 that indicates the flame propagating downstream. The higher velocity group points are generally downstream of the lower velocity group. The points at the lowest $y$ position, in the low speed group, are considered as the flame-base edge velocity $v_{2}$. In the high speed group, the points downstream abutting against the flame edge are considered as $v_{1}$. Thus, $v_{1}, v_{2}$, and 

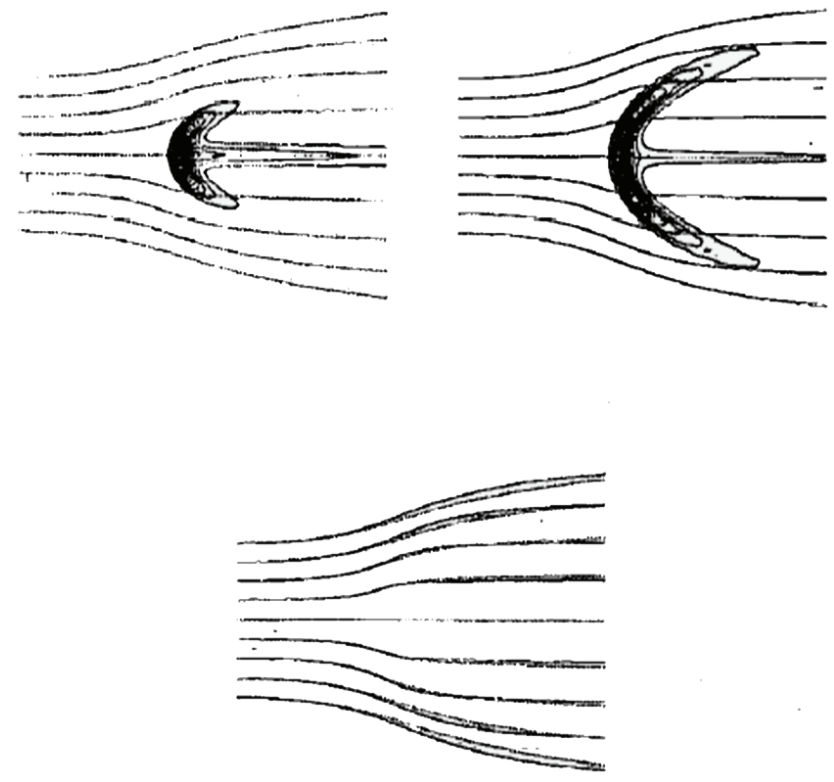

(a)
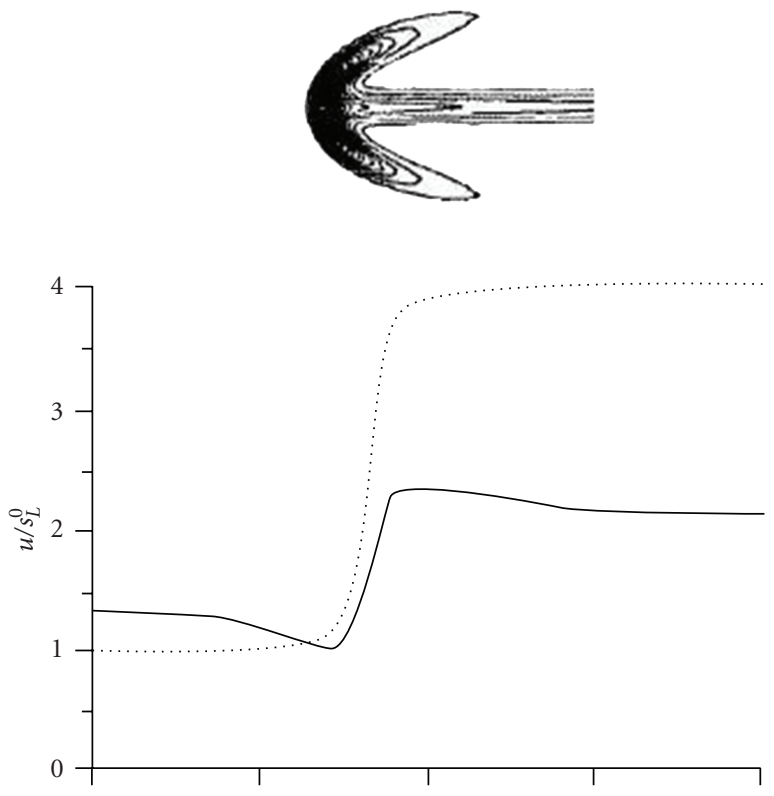

(b)

Figure 2: (a) Streamlines for triple flames with small and large mixing thicknesses. Reprinted by permission of the American Institute of Physics for Ruestch et al. [17], (c) 1995. (b) Contour lines of the reaction rate along with the horizontal velocity component at the stoichiometric or symmetry line for a stabilized triple flame (-) and planar premixed flame (...). Reprinted by permission of the American Institute of Physics for Ruestch et al. [17], (c) 1995.

the ratio of $v_{1} / v_{2}$ could be examined as the characteristics of the reaction-zone edge inside the hot zone and are listed in Table 1.

Subject to a temperature gradient, particles experience a force (thermophoresis) in the direction opposite to that of the temperature gradient. This results in a flame thermal layer slightly thicker than the actual one, and the flame front could move to the region of expanding gases. For particle diameter of $\mathrm{dp}=3 \mu \mathrm{m}$, research has shown that velocity measurement uncertainty with thermophoretic effect is of the order of $\mathrm{cm} / \mathrm{s}$ and less than $3 \mathrm{~cm} / \mathrm{s}$ using the velocity lag profile from Stella et al. [24]. In addition, it decreases with decreasing particle diameter. For seeding particles with a diameter of $0.5 \mu \mathrm{m}$ in our experiments, the maximum uncertainty does not exceed $2 \mathrm{~cm} / \mathrm{s}$. At flame base, our measured velocity data is larger than either $1.16 \mathrm{~m} / \mathrm{s}(116 \mathrm{~cm} / \mathrm{s})$ for group 1 or $0.45 \mathrm{~m} / \mathrm{s}(45 \mathrm{~cm} / \mathrm{s})$ for group 2 that has a much bigger magnitude than the uncertainty. Therefore, thermophoresis does bring some errors into the measuring velocity field, but the magnitudes are small.

Eddies are shown in Figure 3(b) using vorticities. There are sometimes large eddies near flame edges (bases on large vorticity values) such as case 3 and the left flame edge in case 4. Figures 4-9 are corresponding results of 6 cases of Figure 3 which include the methane flame jet fluorescence and PIV images, streamlines passing through flame edges and the velocities fields calculated at their left or right liftedflame edges. Figures 4-9 show some eddies from streamline method directly, which just have small intensities or very lower magnitudes compared to those of Figure 3(b). The "a" and "b" series of Figures 4-9 represent streamlines (constructed by connecting the tangent lines of the velocity vectors) passing through the polygon flame edges. All the magnitudes of velocities of points used to calculate the $v_{1} \mathrm{~s}$ and $v_{2}$ s are labeled directly in either the "c" or " $\mathrm{d}$ " series of figures. In addition, flame edge locations are indicated by oval circles. Since the vector field intensity is much lower than streamlines, the streamlines may not be continued at every point, and they could be overlapped at some locations (3D). Also, the velocity magnitudes are reported in the datasets, and important velocities are given in the figures.

Cases 1, 3, and 5 show three different relative positions between the flame base and eddy in the vicinity of the base. In case 1 , the eddy is just higher than flame edge, while an eddy located just lower than the flame edge in case 3 and an eddy position much lower than the flame edge is shown in case 5. These observations support the notion that flame edge positions have no special relationship with the presence of an eddy.

Both cases 2 and 4 have no obvious eddies near the flame base. These streamline distributions near flame edges are the most common situations witnessed in our experiments. However, case 2 has a streamline divergence toward both fuel and air sides; case 4 streamlines only diverge toward one side, either the air side (case 4, flame left edge) or the fuel side (case 4, flame right edge).

The streamline distributions in case 6 are rarely witnessed in the experimental results. Because of the eddy slow rotational speeds, the spiral motion focuses as singular points are easily captured by streamlines. The eddy morphology of case 6 at the left or right flame edge is also different. The left edge's eddy only twists toward downstream directions (with 


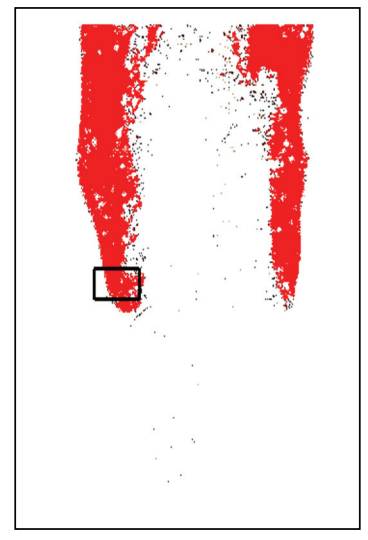

(Case 1)

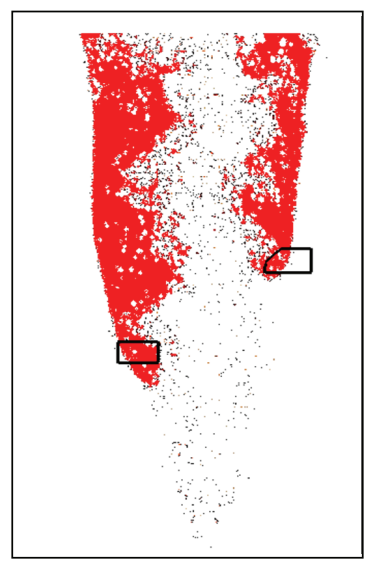

(Case 4)

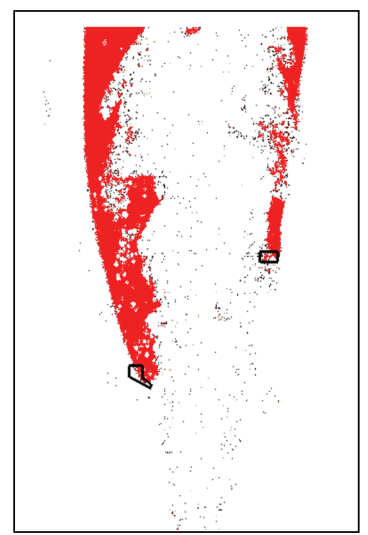

(Case 2)

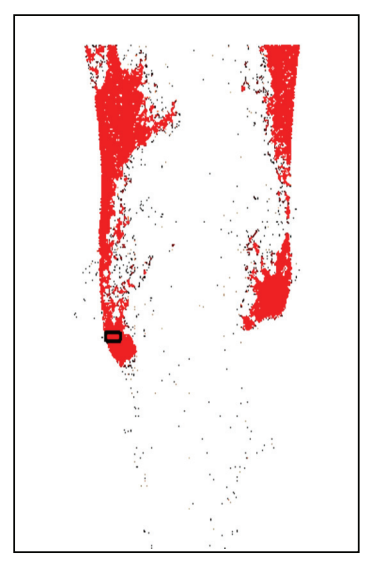

(Case 5)

(a)

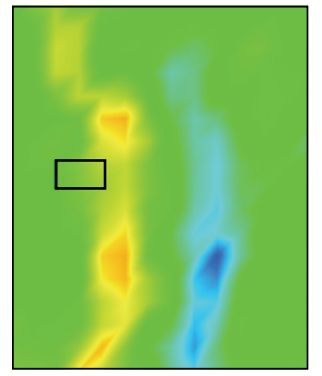

(Case 1)

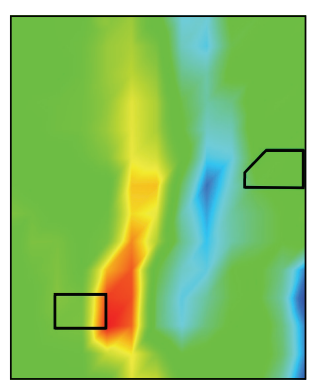

(Case 4)

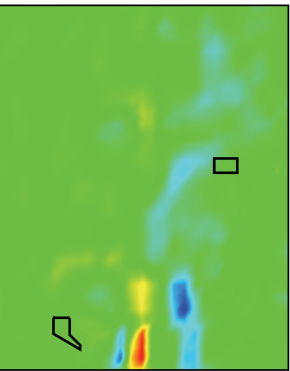

(Case 2)

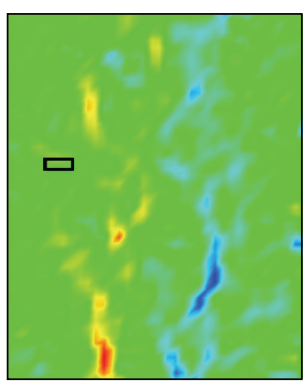

(Case 5)

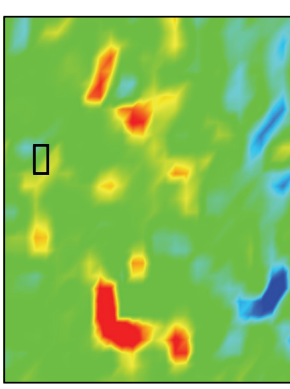

(Case 3)

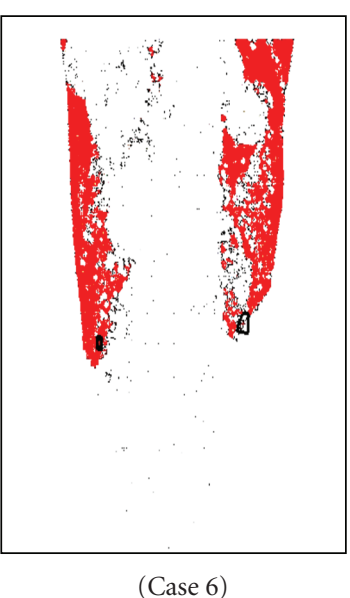

(Case 6)

Vorticity

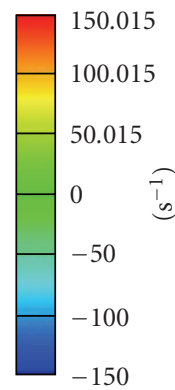

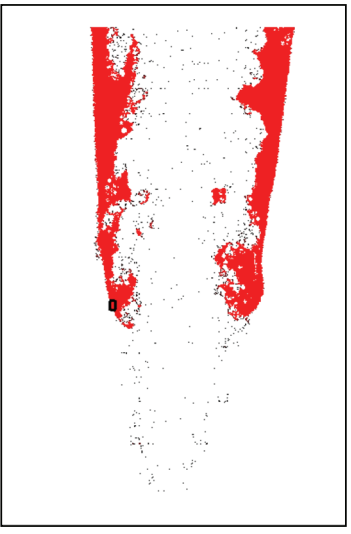

(Case 3)

Vorticity

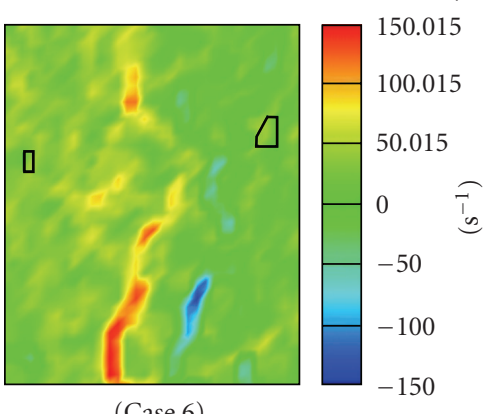

(Case 6)

(b)

Figure 3: (a) High temperature zones and flame edges (polygons). (b) Flame edges (polygons) and vorticities distribution. 


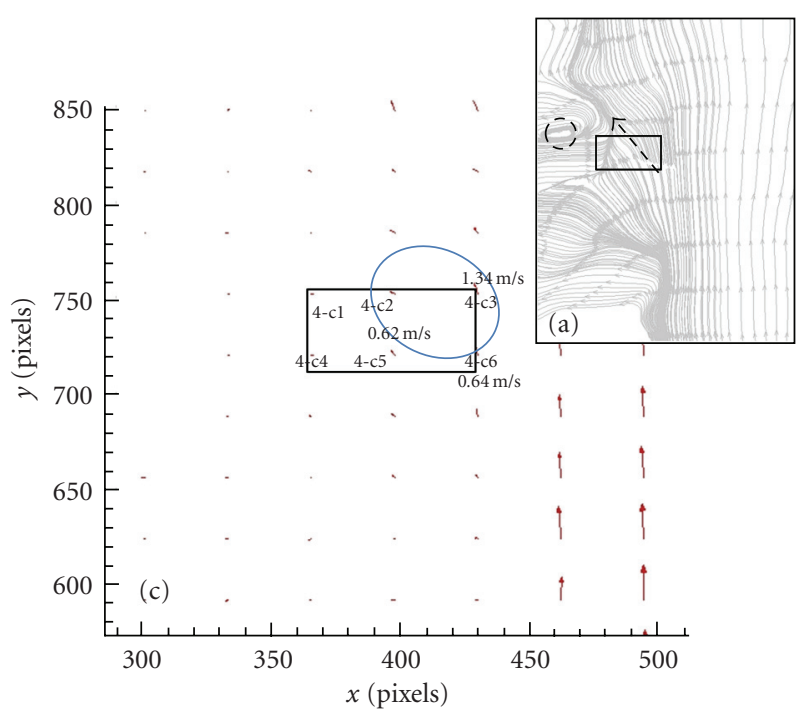

FIgURE 4: (a) Streamlines passing through the flame edge of case 1. (c) Velocity variation at the flame edge of case 1 . The velocities in the rectangle are $0.28 \mathrm{~m} / \mathrm{s}, 0.62 \mathrm{~m} / \mathrm{s}, 1.34 \mathrm{~m} / \mathrm{s}, 0.35 \mathrm{~m} / \mathrm{s}, 0.5 \mathrm{~m} / \mathrm{s}$, and $0.64 \mathrm{~m} / \mathrm{s}$ (ordered by left to right and top down).

a $90^{\circ}$ range), while the right one twists in all directions (with a $360^{\circ}$ range).

The six cases represent the general characteristics of the streamline and interrelated eddy styles near flame edges. In Figure 4 through Figure 9, dashed arrow straight lines indicate the streamline divergence directions, dashed circles label the eddy positions, and dashed triangles probe the singular points.

Figure 4 series are the results of methane jet flame image of case 1 . The rectangle box is supposed to include the flame edge because of the biggest velocity gradient and streamlines divergence there. The velocity of point $4-c 3,1.34 \mathrm{~m} / \mathrm{s}$, is the largest in the rectangle. The other five points $4-\mathrm{c} 1,4-$ c2, 4-c4, 4-c5, and 4-c6 have much smaller velocities, and the points $4-c 2$ and $4-c 6$ are abutting against point $4-c 3$. So the $v_{2}$, for this figure, is the average of points $4-\mathrm{c} 2$ and $4-\mathrm{c} 6$, which is $0.63 \mathrm{~m} / \mathrm{s}$, and the $v_{1}$, considered at point 4$\mathrm{c} 3$, is $1.34 \mathrm{~m} / \mathrm{s}$. This is consistent with the morphology of the chemiluminescence zone and the jump in velocity being approximately 2, representing the flow into the premixed edge of the reaction zone.

Figure 5 series show the results of methane jet flame image of case 2. The flame edges are contained in the polygons (in Figures 5(c) and 5(d)). The $v_{2}$ in Figure 5(c) is $0.7 \mathrm{~m} / \mathrm{s}$, which is the average of points $5-\mathrm{cl}$ and $5-\mathrm{c} 3$, and the $v_{1}$ is the value of $5-\mathrm{c} 2,1.7 \mathrm{~m} / \mathrm{s}$. In Figure $5(\mathrm{~d})$, the $v_{2}$, $0.64 \mathrm{~m} / \mathrm{s}$, is the average of the three points in the top line of the rectangle, and the $v_{1}$ is the average of 5-d1 and 5-d2 which is $1.375 \mathrm{~m} / \mathrm{s}$. At this right flame edge, air is seen to be strongly entrained.

Figure 6 series are the results of methane jet flame image of case 3. Figure 6(a) shows that there is a large eddy nearby the left flame edge, where air is coming into the flame edge significantly. The $v_{2}, 0.737 \mathrm{~m} / \mathrm{s}$, is the average of the three points of 6-c4, 6-c5, and 6-c6 in the rectangle, while the $v_{1}$
TABLE 1: Velocity magnitudes and ratios at flame edges.

\begin{tabular}{llll}
\hline & $\begin{array}{l}\text { Velocity of } \\
\text { fownstream } \\
\text { Figure no. to flame } \\
\text { edge: } v_{1}(\mathrm{~m} / \mathrm{s})\end{array}$ & $\begin{array}{l}\text { Velocity of flame } \\
\text { edge upstream: } \\
v_{2}(\mathrm{~m} / \mathrm{s})\end{array}$ & Ratio of $v_{1} / v_{2}$ \\
\hline $4(\mathrm{c})$ & 1.34 & 0.63 & 2.13 \\
$5(\mathrm{c})$ & 1.7 & 0.7 & 2.43 \\
$5(\mathrm{~d})$ & 1.375 & 0.64 & 2.15 \\
$6(\mathrm{c})$ & 1.767 & 0.737 & 2.4 \\
$7(\mathrm{c})$ & 1.66 & 0.64 & 2.59 \\
$7(\mathrm{~d})$ & 1.685 & 0.695 & 2.42 \\
$8(\mathrm{c})$ & 1.16 & 0.45 & 2.58 \\
$9(\mathrm{c})$ & 1.41 & 0.55 & 2.56 \\
$9(\mathrm{~d})$ & 1.34 & 0.53 & 2.53 \\
\hline Average & 1.49 & 0.62 & 2.42 \\
\hline
\end{tabular}

is $1.767 \mathrm{~m} / \mathrm{s}$, which is the average of points $6-\mathrm{c} 1,6-\mathrm{c} 2$, and 6-c3.

Figure 7 series show both left (Figure $7(\mathrm{c})$ ) and right (Figure 7(d)) flame edges of case 4. At the left flame edge, the $v_{2}$ is the average of points $7-c 1,7-c 4$, and 7-c5, which is $0.64 \mathrm{~m} / \mathrm{s}$, and the $v_{1}$ is $1.66 \mathrm{~m} / \mathrm{s}$, the average of points 7-c2, 7$\mathrm{c} 3$, and 7-c6. At the right flame edge, the $v_{2}$ is the average of points $7-\mathrm{d} 3$ and $7-\mathrm{d} 4$, which is $0.695 \mathrm{~m} / \mathrm{s}$, while the $v_{1}$ is $1.685 \mathrm{~m} / \mathrm{s}$, the average of points $7-\mathrm{d} 1$ and $7-\mathrm{d} 2$. Figure 8 series (of case 5) are the fifth results. Figure 8(c) shows the left flame edge with the $v_{2}$ as the average of the upper line points in the rectangle, which is $0.45 \mathrm{~m} / \mathrm{s}$, and the $v_{1}$, the average of $8-\mathrm{c} 1,8-\mathrm{c} 2$, and $8-\mathrm{c} 3$, is $1.16 \mathrm{~m} / \mathrm{s}$. The streamlines at the left flame edge indicate flow towards the surrounding air, which is significant.

In Figure 9 (of case 6), at the left flame edge in Figure $9(\mathrm{c})$, the $v_{2}$ is $0.55 \mathrm{~m} / \mathrm{s}$ which is calculated by the average of points of $0.47 \mathrm{~m} / \mathrm{s}, 0.44 \mathrm{~m} / \mathrm{s}$ and $0.73 \mathrm{~m} / \mathrm{s}$, while the $v_{1}$ is $1.41 \mathrm{~m} / \mathrm{s}$, the average of points $9-\mathrm{c} 1,9-\mathrm{c} 2$, and 9 c3. At the right flame edge in Figure 9(d), the $v_{2}$ is set as the average of point 9-d4, 9-d5, and 9-d6 which has the value of $0.53 \mathrm{~m} / \mathrm{s}$, and the $v_{1}$ is $1.34 \mathrm{~m} / \mathrm{s}$, set as the average of points $9-\mathrm{d} 1$ and $9-\mathrm{d} 2$. The right flame edge has what appears to be a large-scale vertical structure at the jet edge.

Analyzing the selected data, the streamlines in Figure 4 through Figure 9 are compared near the flame edges with the streamlines of a triple flame in Figure 2. In the current experimental results, the streamlines into the reaction zones have similar trends and divergences, as one would expect from a triple flame and laminar lifted-flame [25] structures. Virtually all of trends in Figures 4 to 9 show that the streamlines evolve to near straight parallel lines above the initial divergences positions, similar to what is witnessed in the triple flame simulations. Figures $5(\mathrm{a})$ and $5(\mathrm{~b})$ streamlines diverge toward the two sides (both fuel and air). While the results of Figures 4(a), 6(a), 7(a), 8(a), 9(a), and 9 (b) show similar divergences to air side. The other result of Figure 7(b) shows streamlines directed toward fuel side. In addition, the present study finds that the eddies near the flame edge, such as Figures 4(a), 6(a), 8(a), 9(a), and 9(b) 

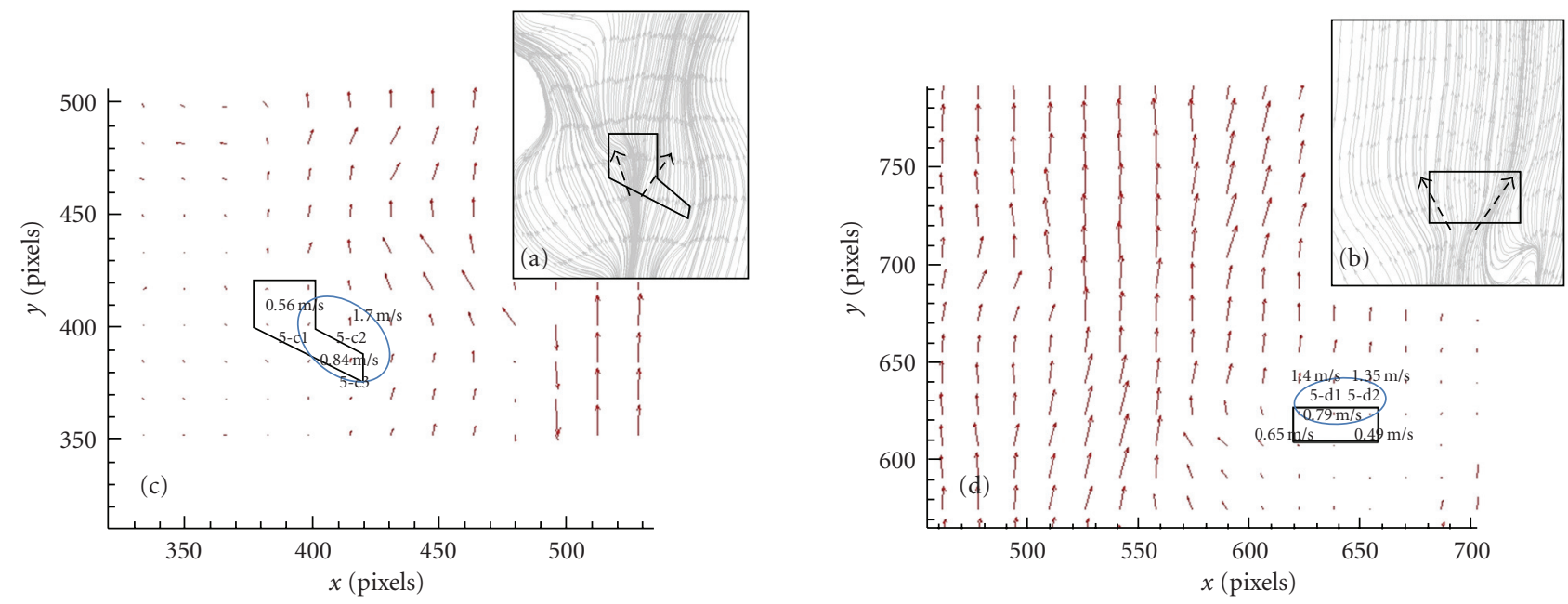

Figure 5: (a) and (b) Streamlines passing through the left (a) and right (b) flame edges of case 2. (c) Velocity variation at the left flame edge of case 2. The points' velocities in the polygon are $0.42 \mathrm{~m} / \mathrm{s}, 0.8 \mathrm{~m} / \mathrm{s}, 0.56 \mathrm{~m} / \mathrm{s}, 0.56 \mathrm{~m} / \mathrm{s}$, and $0.84 \mathrm{~m} / \mathrm{s}$ (ordered by left to right and top down). The velocity of point $5-\mathrm{c} 2$ is $1.7 \mathrm{~m} / \mathrm{s}$. (d) Velocity variation at the right flame edge of case 2 . The six points' velocities in the rectangle are $0.65 \mathrm{~m} / \mathrm{s}, 0.79 \mathrm{~m} / \mathrm{s}, 0.49 \mathrm{~m} / \mathrm{s}, 0.21 \mathrm{~m} / \mathrm{s}, 0.2 \mathrm{~m} / \mathrm{s}$, and $0.07 \mathrm{~m} / \mathrm{s}$ (ordered by left to right, top down). The velocities of points 5-d1 and 5-d2 are $1.4 \mathrm{~m} / \mathrm{s}$ and $1.35 \mathrm{~m} / \mathrm{s}$.

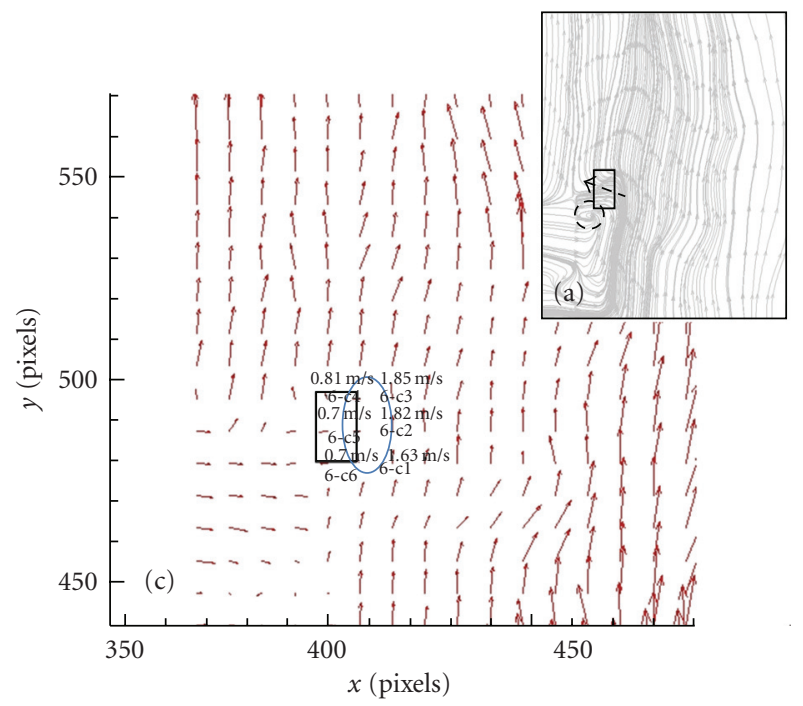

Figure 6: (a) Streamlines passing through the flame edge of case 3. (c) Velocity variation at the flame edge of case 3 . The velocities of the six points in the rectangle are $1.06 \mathrm{~m} / \mathrm{s}, 0.81 \mathrm{~m} / \mathrm{s}, 0.92 \mathrm{~m} / \mathrm{s}$, $0.7 \mathrm{~m} / \mathrm{s}, 0.81 \mathrm{~m} / \mathrm{s}$, and $0.7 \mathrm{~m} / \mathrm{s}$ (ordered by left to right, top down). The velocities of the three points of 6-c1, 6-c2, and 6-c3 are $1.63 \mathrm{~m} / \mathrm{s}$, $1.82 \mathrm{~m} / \mathrm{s}$, and $1.85 \mathrm{~m} / \mathrm{s}$.

flow fields, are similar to those seen in the work of Kelman et al. [6].

All of these cases show that air is entrained into the reaction zone regardless of the existence of a large eddy near flame edge. It was also shown by Domingo and Vervisch [26] that a triple flame is able to survive strong interaction with vortices by adjusting its structure to a new transient environment. In addition, no evidence supports this flame edge as the large eddy is a one sequence of flame edge evolutions since only one large eddy at most could be found near flame edge. There is no evidence to indicate that the flame edges must be located at a fixed vortex position, such as the second or third vortex starting from jet inlet. It only offers that flame edge may stretch and has not the whole triple flame shape. The fuel lean, fuel rich, and diffusion tribrachial structure (triple flame) at the flame edge may lose one or two premix branches and merge into the trailing diffusion flame, which has been examined in previous studies and is still an area of contention.

Ruetsch et al. [17] performed a theoretical and computational study of triple flames, results of which are shown in Figure 2(b). For small cross-stream gradients in mixture fraction, the flame propagation speed is $u_{F} \approx s_{L} \sqrt{\rho_{u} / \rho_{d}}$, where $u_{F}$ is the flame speed relative to the flow well upstream, $s_{L}$ is the stoichiometric laminar flame speed, and $\rho_{u}$ and $\rho_{d}$ are the densities far upstream and far downstream of the flame. For an upstream stoichiometric methane-air mixture at $298 \mathrm{~K}$, where the downstream mixture consists of combustion products at $2210 \mathrm{~K}, u_{F} \approx 2.4 s_{L}$. The flame inflow axial velocities measured by Muñiz and Mungal [16] and by Han and Mungal [22] were typically less than $\approx 3 s_{L}$.

In the present experiments, velocity magnitudes of the flame-base edge range from 0.45 to $0.737 \mathrm{~m} / \mathrm{s}$ and the $v_{1} \mathrm{~s}$, which is the next to the flame edge velocities, range from 1.16 to $1.767 \mathrm{~m} / \mathrm{s}$. These generally agree with the heat release effect proposed by Boulanger et al. [27]. They support the notion that in lifted jet flames, the effect of the heat release causes the deflection of the flow upstream of the curved front, which has the net result of making the reaction propagate faster than $s_{L}$, the propagation speed of a fully premixed and planar stoichiometric flame. This flow deflection also induces a decrease of the mixture fraction gradient in the trailing diffusion flame. The velocity of the overall reaction zone structure is therefore greater than the premixed burning velocity. 

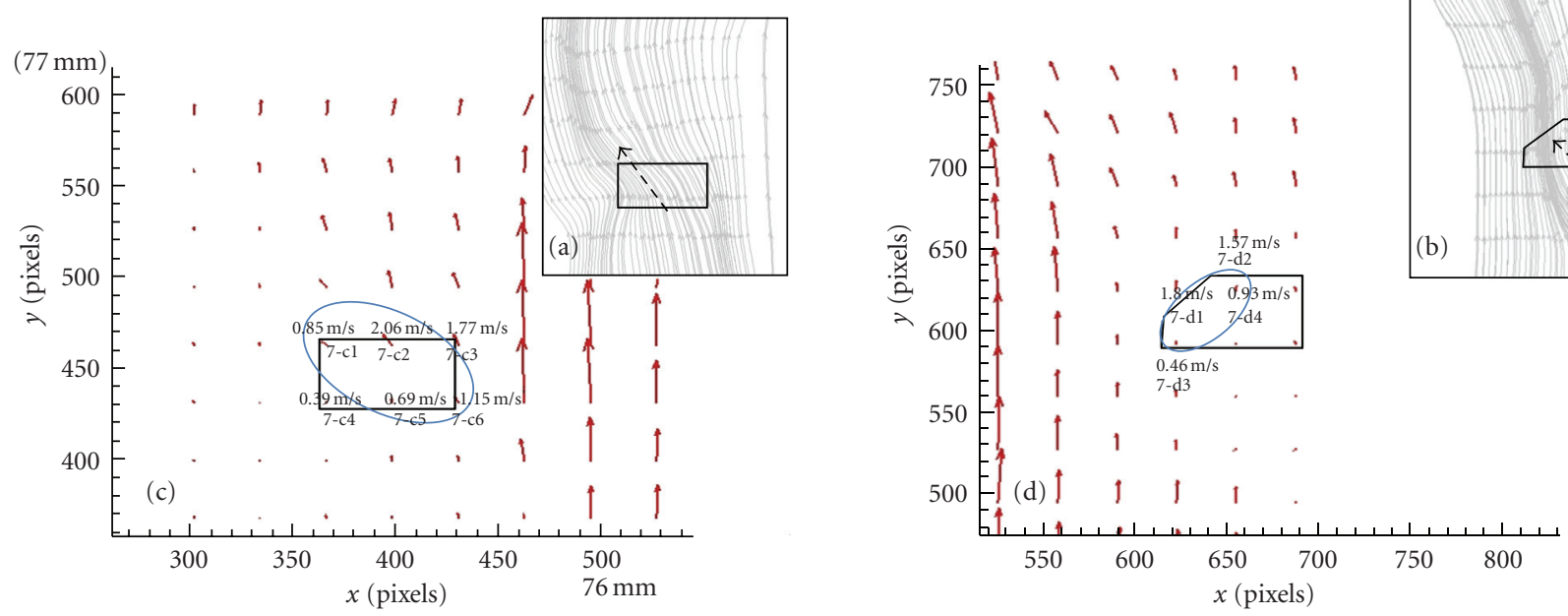

FIGURE 7: (a) and (b) Streamlines passing through the left (a) and right (b) flame edges of case 4. (c) Velocity variation at the left flame edge of case 4 . The points' velocities in the polygon are $0.85 \mathrm{~m} / \mathrm{s}, 2.06 \mathrm{~m} / \mathrm{s}, 1.77 \mathrm{~m} / \mathrm{s}, 0.39 \mathrm{~m} / \mathrm{s}, 0.69 \mathrm{~m} / \mathrm{s}$, and $1.15 \mathrm{~m} / \mathrm{s}$ (ordered by left to right, top down). (d) Velocity variation at the right flame edge of case 4 . The points' velocities in the polygon are $0.93 \mathrm{~m} / \mathrm{s}, 0.66 \mathrm{~m} / \mathrm{s}, 0.46 \mathrm{~m} / \mathrm{s}, 0.42 \mathrm{~m} / \mathrm{s}$, and $0.45 \mathrm{~m} / \mathrm{s}$ (ordered by left to right, top down). The velocities of points $7-\mathrm{d} 1$ and $7-\mathrm{d} 2$ are $1.8 \mathrm{~m} / \mathrm{s}$ and $1.57 \mathrm{~m} / \mathrm{s}$, respectively.

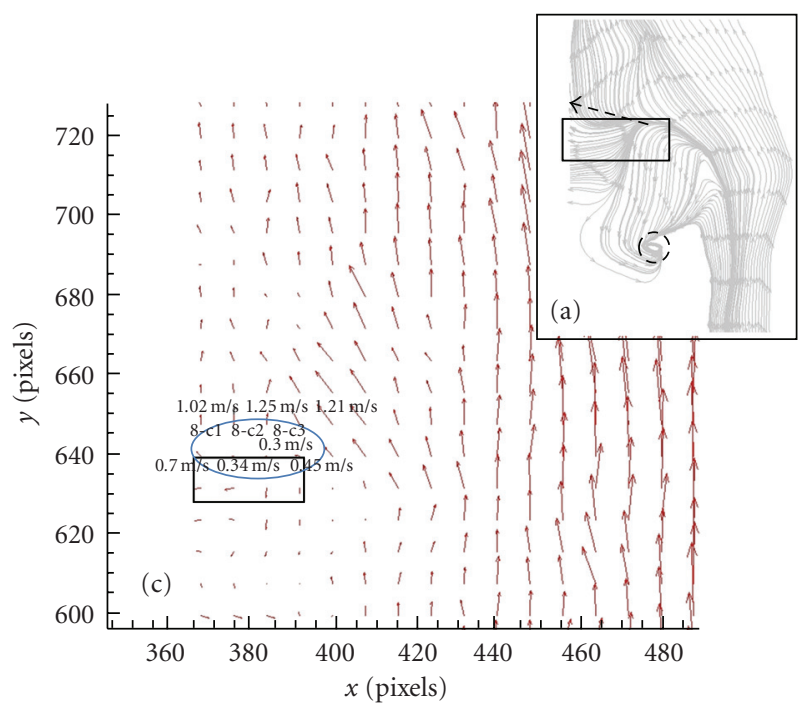

FIGURE 8: (a) Streamlines passing through the left flame edge of case 5. (c) Velocity variation at the flame edge of case 5. The points' velocities in the rectangle are $0.7 \mathrm{~m} / \mathrm{s}, 0.34 \mathrm{~m} / \mathrm{s}, 0.30 \mathrm{~m} / \mathrm{s}, 0.45 \mathrm{~m} / \mathrm{s}, 0.71 \mathrm{~m} / \mathrm{s}, 0.99 \mathrm{~m} / \mathrm{s}, 1.0 \mathrm{~m} / \mathrm{s}$, and $0.8 \mathrm{~m} / \mathrm{s}$ (ordered by left to right, top down). The velocities of $8-\mathrm{c} 1,8-\mathrm{c} 2$, and $8-\mathrm{c} 3$ points are $1.02 \mathrm{~m} / \mathrm{s}, 1.25 \mathrm{~m} / \mathrm{s}$, and $1.21 \mathrm{~m} / \mathrm{s}$.

A summary of the aforementioned discussion, however varied, results in the identification of a trend through the data shown in Table 1. Most results (Table 1) indicate that the local velocities are larger than $0.4 \mathrm{~m} / \mathrm{s}$. This also agrees with Upatnieks et al. [11], which found that the effective propagation velocity of the entire edge flame with respect to the upstream (undisturbed) flow exceeds the laminar burning velocity. Ghosal and Vervisch [28] introduced a heat release effect parameter $\alpha=\left(T_{s}-T_{0}\right) / T_{s}$, where $T_{0}$ is the temperature of the fresh gases and $T_{s}$ is the adiabatic temperature of a stoichiometric flame. In typical hydrocarbon flames, $\alpha$ is 0.8 , and the flow speed at the base of the lifted flame (equal to the triple flame speed) is almost twice the adiabatic flame speed for the corresponding stoichiometric mixture. In the present results, the flame edge speed $v_{2}$ is larger than laminar flame speed, but less than twice of the laminar speed. Chung [29] showed the laminar flame edge has different velocities at transition (larger than $s_{L}$ ), tribrachial (close to $s_{L}$ ), bibrachial (smaller than $s_{L}$, sometimes negative), and monobrachial (negative close to extinction); however, our results only showed that the velocities are larger than $s_{L}$ and there are no clues about the bibrachial and monobranchial phenomena.

In addition, shown in Table 1, the average ratio, of velocity magnitudes at the flame-base edge, is approximately 2.42 (ranged from 2.13 to 2.59 ), which is rather close to that 

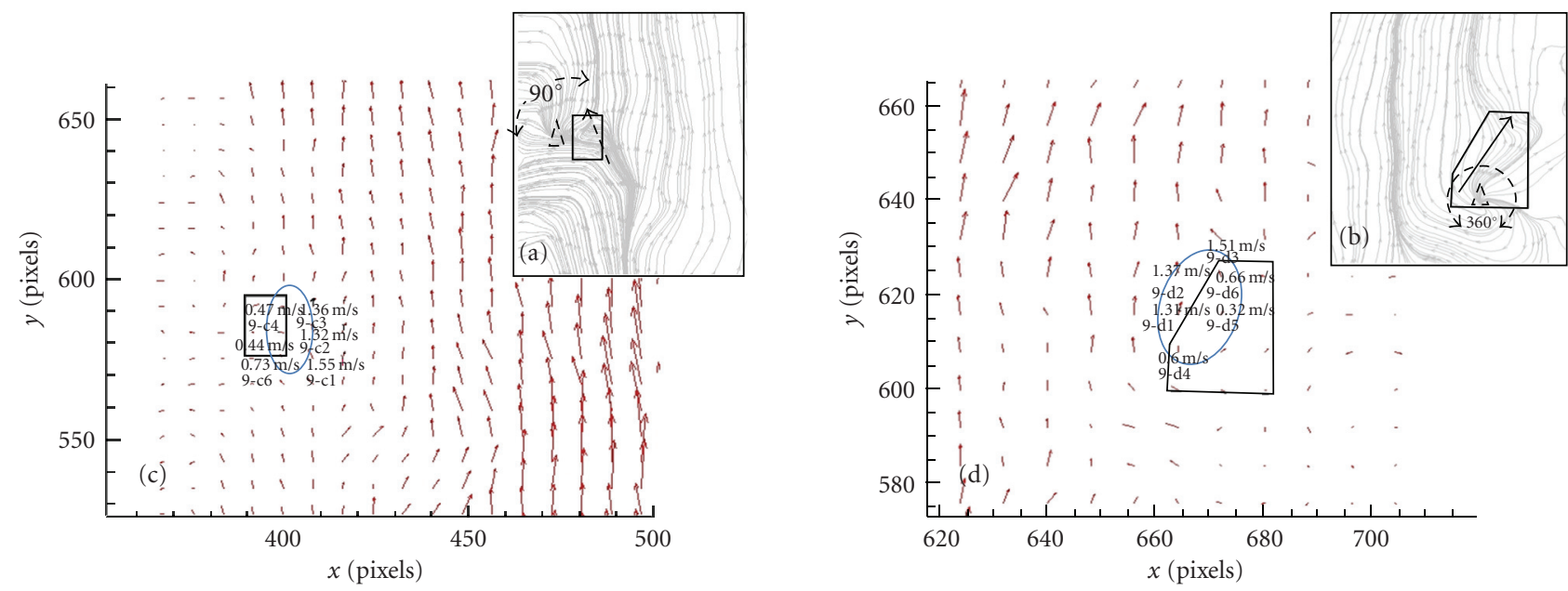

FIGURE 9: (a) and (b) Streamlines passing through the left (a) and right (b) flame edges of case 6. (c) Velocity variation at the left flame edge of case 6 . The points' velocities in the polygon are $0.76 \mathrm{~m} / \mathrm{s}, 0.47 \mathrm{~m} / \mathrm{s}, 0.17 \mathrm{~m} / \mathrm{s}, 0.44 \mathrm{~m} / \mathrm{s}, 0.54 \mathrm{~m} / \mathrm{s}$, and $0.73 \mathrm{~m} / \mathrm{s}$ (ordered by left to right, top down). The velocities of 9-c1, 9-c2, and $9-\mathrm{c} 3$ are $1.55 \mathrm{~m} / \mathrm{s}, 1.32 \mathrm{~m} / \mathrm{s}$, and $1.36 \mathrm{~m} / \mathrm{s}$. (d) Velocity variation at the right flame edge of case 6. The points' velocities in the polygon speeds are $0.66 \mathrm{~m} / \mathrm{s}, 0.37 \mathrm{~m} / \mathrm{s}, 0.32 \mathrm{~m} / \mathrm{s}, 0.41 \mathrm{~m} / \mathrm{s}, 0.6 \mathrm{~m} / \mathrm{s}, 0.54 \mathrm{~m} / \mathrm{s}, 0.53 \mathrm{~m} / \mathrm{s}, 0.69 \mathrm{~m} / \mathrm{s}, 0.33 \mathrm{~m} / \mathrm{s}$, and $0.23 \mathrm{~m} / \mathrm{s}$ (ordered by left to right, top down). The velocities of points $9-\mathrm{d} 1,9-\mathrm{d} 2$, and $9-\mathrm{d} 3$ are $1.31 \mathrm{~m} / \mathrm{s}, 1.37 \mathrm{~m} / \mathrm{s}$, and $1.51 \mathrm{~m} / \mathrm{s}$.

of a typical triple flame, of 2.4 , than a planar premixed flame, of 4 . This agrees with the flame-edge concept supported by Upatnieks et al. [11], and their data also show no significant correlation between propagation speed and the passage of large eddies.

\section{Conclusions}

The data presented shows the presence of a velocity field consistent with that of a partially premixed edge flame.

(1) The flame edges (next to the polygons in the flame images) reveal that the streamlines have similar divergence characteristics to edge flames. Above the flame edge location, the streamlines downstream have nearly straight parallel arrangements, which are also similar to that modeled triple flames in studies. The divergences can be located in large eddies, but are not in some cases, and still indicate fuel and air mixed at the flame edge. This is similar as the claim by Upatnieks et al. [11] that the flame base does not need to be in contact with eddies to remain anchored at one fixed location, and the large eddies could be just a factor in flame base oscillation. However, the detailed flame edge structure is still not clearly rendered; it might be tribrachial, bibrachial, or monobrachial and the mass fractions' gradients are not obtained in the present experiments-the edge flame propagation speed with concentration gradient supports the flame edge detailed structures (Chung [29]). Therefore, in this Re case, the lift-off jet flame stability is argued to be driven by a partially premixed flame mechanism.

(2) The propagation velocities at the flame edge are, in general, higher than those of the corresponding laminar triple flames. The flame edge speed $v_{2}$ is larger than laminar speed $s_{L}(0.4 \mathrm{~m} / \mathrm{s})$, and the $v_{1}$ downstream next to the flame edge is larger than $0.96 \mathrm{~m} / \mathrm{s}$ which is approximately $2.4 s_{L}$.

(3) Using relatively primitive particle tracking/PIV and chemiluminescence techniques, meaningful facets of the reaction zone can be extracted, as evidenced from the results summarized in Table 1.

\section{Acknowledgment}

The research reported in this paper has been partially supported by the U.S. Army Research Office (Contract W911NF0810142).

\section{References}

[1] W. M. Pitts, "Assessment of theories for the behaviour and blowout of lifted turbulent jet diffusion flames," in Proceedings of the 22nd International Symposium on Combustion, pp. 809816, The Combustion Institute, Pittsburgh, Pa, USA, 1988.

[2] K. M. Lyons, "Toward an understanding of the stabilization mechanisms of lifted turbulent jet flames: experiments," Progress in Energy and Combustion Science, vol. 33, no. 2, pp. 211-231, 2007.

[3] L. Vanquickenborne and A. van Tiggelen, "The stabilization mechanism of lifted diffusion flames," Combustion and Flame, vol. 10, no. 1, pp. 59-69, 1966.

[4] K. Wohl, N. M. Kapp, and G. Gazley, "The stability of open flames," in Proceedings of the 3rd International Symposium on Combustion, pp. 3-21, The Combustion Institute, Pittsburgh, Pa, USA, 1949.

[5] C. P. Burgess and C. J. Lawn, "The premixture model of turbulent burning to describe lifted jet flames," Combustion and Flame, vol. 119, no. 1-2, pp. 95-108, 1999.

[6] J. B. Kelman, A. J. Eltobaji, and A. R. Masri, "Laser imaging in the stabilization region of turbulent lifted flames," Combustion Science and Technology, vol. 135, no. 1-6, pp. 117-134, 1998. 
[7] K. A. Watson, K. M. Lyons, J. M. Donbar, and C. D. Carter, "On scalar dissipation and partially premixed flame propagation," Combustion Science and Technology, vol. 175, no. 4, pp. 649-664, 2003.

[8] R. W. Schefer and P. J. Goix, "Mechanism of flame stabilization in turbulent, lifted-jet flames," Combustion and Flame, vol. 112, no. 4, pp. 559-574, 1998.

[9] N. Peters and F. A. Williams, "Liftoff characteristics of turbulent jet diffusion flames," AIAA Journal, vol. 21, no. 3, pp. 423-429, 1983.

[10] G. T. Kalghatgi, "Lift-off heights and visible lengths of vertical turbulent jet diffusion flames in still air," Combustion Science and Technology, vol. 41, pp. 17-29, 1984.

[11] A. Upatnieks, J. F. Driscoll, C. C. Rasmussen, and S. L. Ceccio, "Liftoff of turbulent jet flames-assessment of edge flame and other concepts using cinema-PIV," Combustion and Flame, vol. 138, no. 3, pp. 259-272, 2004.

[12] R. C. Miake-Lye and J. A. Hammer, "Lifted turbulent jet flames: a stability criterion based on the jet large-scale structure," in Proceedings of the 22nd International Symposium on Combustion, pp. 817-824, The Combustion Institute, Pittsburgh, Pa, USA, 1988.

[13] D. Damare and F. Baillot, "The role of secondary instabilities in the stabilization of a nonpremixed lifted jet flame," Physics of Fluids, vol. 13, no. 9, pp. 2662-2670, 2001.

[14] J. D. Buckmaster and R. O. Weber, "Edge flame holding," Proceedings of Combustion Institute, vol. 26, pp. 1143-1149, 1996.

[15] J. Buckmaster and R. Weber, "Edge-flame-holding," Proceedings of Combustion Institute, vol. 26, no. 1, pp. 1143-1149, 1996.

[16] L. Muñiz and M. G. Mungal, "Instantaneous flamestabilization velocities in lifted-jet diffusion flames," Combustion and Flame, vol. 111, no. 1-2, pp. 16-31, 1997.

[17] G. R. Ruetsch, L. Vervisch, and A. Liñán, "Effects of heat release on triple flames," Physics of Fluids, vol. 7, no. 6, pp. 1447-1454, 1995.

[18] M. S. Mansour, A. Joedicke, and N. Peters, "Multi-reaction zones imaging technique for turbulent hydrocarbon flames," Turkish Journal of Engineering \& Environmental Sciences, vol. 30, no. 3, pp. 157-161, 2006.

[19] K. A. Watson, K. M. Lyons, J. M. Donbar, and C. D. Carter, "Scalar and velocity field measurements in a lifted CH4-air diffusion flame," Combustion and Flame, vol. 117, no. 1-2, pp. 257-271, 1999.

[20] D. Veynante, L. Vervisch, T. Poinsot, L. Liñán, and G. Ruetsch, "Triple flame structure and diffusion flame stabilization," in Proceedings of the Summer Program, pp. 55-73, Center for Turbulence Research, Sanford, Calif, USA, 1994.

[21] L. K. Su, O. S. Sun, and M. G. Mungal, "Experimental investigation of stabilization mechanisms in turbulent, lifted jet diffusion flames," Combustion and Flame, vol. 144, no. 3, pp. 494-512, 2006.

[22] D. Han and M. G. Mungal, "Simultaneous measurement of velocity and $\mathrm{CH}$ layer distribution in turbulent non-premixed flames," Proceedings of the Combustion Institute, vol. 28, no. 1, pp. 261-267, 2000.

[23] J. Westerweel, "Fundamentals of digital particle image velocimetry," Measurement Science \& Technology, vol. 8, no. 12, pp. 1379-1392, 1997.

[24] A. Stella, G. Guj, J. Kompenhans, M. Raffel, and H. Richard, "Application of particle image velocimetry to combusting flows: design considerations and uncertainty assessment," Experiments in Fluids, vol. 30, no. 2, pp. 167-180, 2001.
[25] B. J. Lee and S. H. Chung, "Stabilization of lifted tribrachial flames in a laminar nonpremixed jet," Combustion and Flame, vol. 109, no. 1-2, pp. 163-172, 1997.

[26] P. Domingo, L. Vervisch, and D. Veynante, "Large-eddy simulation of a lifted methane jet flame in a vitiated coflow," Combustion and Flame, vol. 152, no. 3, pp. 415-432, 2008.

[27] J. Boulanger, L. Vervisch, J. Reveillon, and S. Ghosal, "Effects of heat release in laminar diffusion flames lifted on round jets," Combustion and Flame, vol. 134, no. 4, pp. 355-368, 2003.

[28] S. Ghosal and L. Vervisch, "Stability diagram for lift-off and blowout of a round jet laminar diffusion flame," Combustion and Flame, vol. 124, no. 4, pp. 646-655, 2001.

[29] S. H. Chung, "Stabilization, propagation and instability of tribrachial triple flames," Proceedings of the Combustion Institute, vol. 31, pp. 877-892, 2007. 

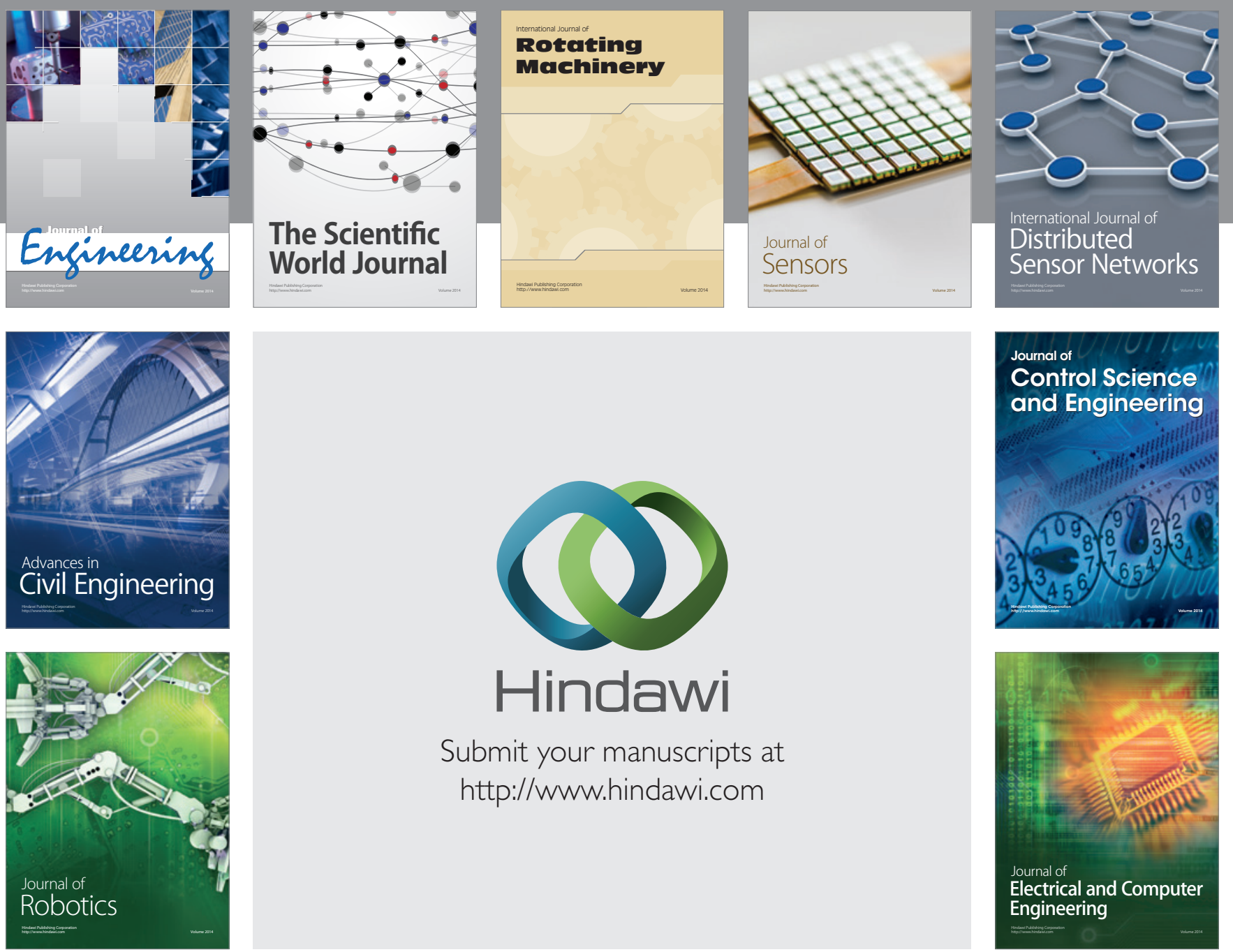

Submit your manuscripts at

http://www.hindawi.com
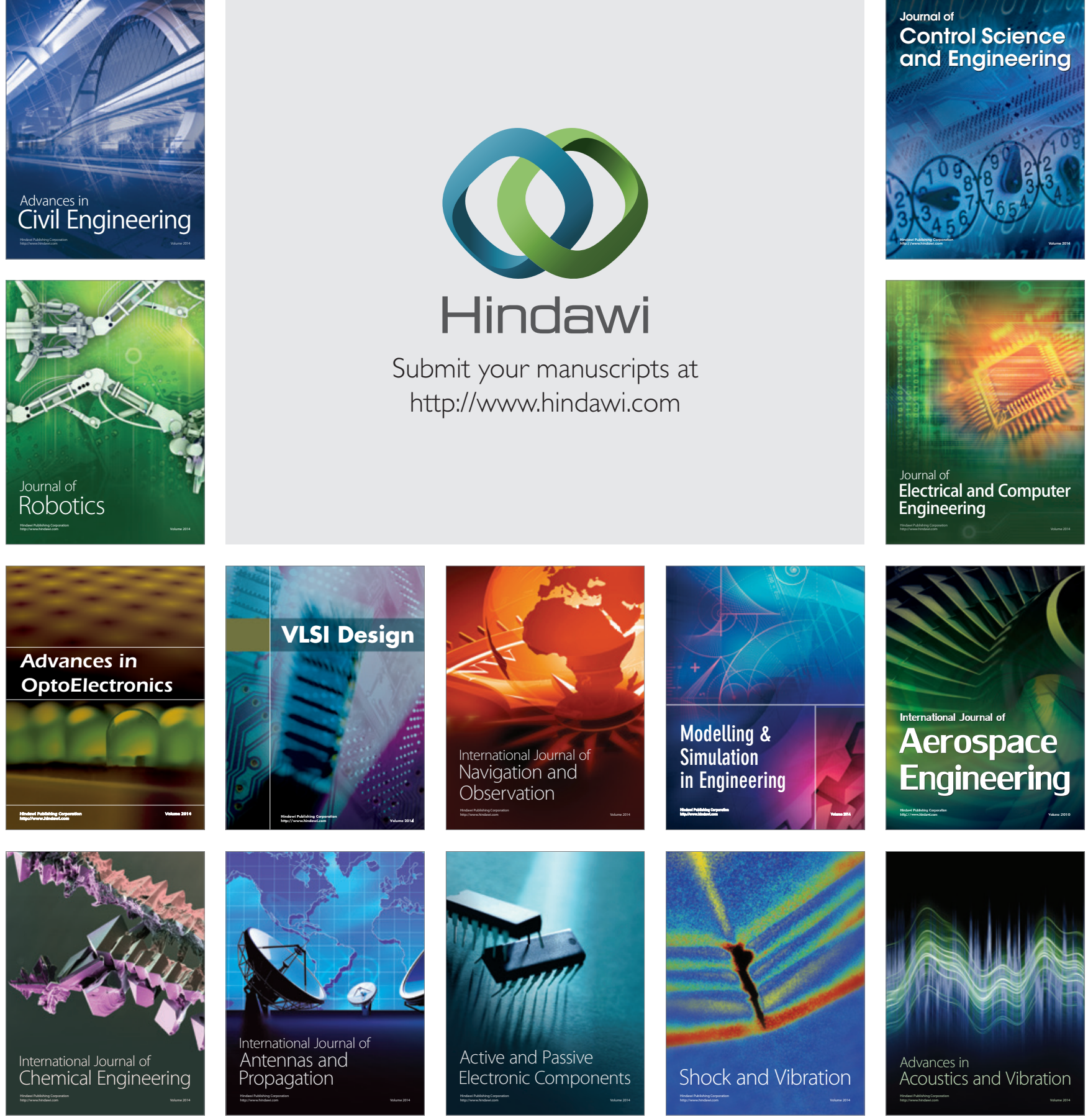